\title{
A Case Report of Stroke While Driving: Minor Traumas Might be not Minor at all
}

\author{
Entela Basha ${ }^{1}$, Eris Ranxha ${ }^{1}$, Vojsava Leka ${ }^{2}$, Gentian Vyshka ${ }^{3,}{ }^{*} \mathrm{C}$ \\ 1 Stroke Unit, University Hospital Centre "Mother Teresa" Tirana, Albania \\ ${ }^{2}$ Neurology Department, International Hospital Tirana, Albania \\ ${ }^{3}$ Biomedical and Experimental Department, Faculty of Medicine, University of Medicine in Tirana, Albania \\ *Correspondence: gvyshka@gmail.com
}

\begin{abstract}
Stroke while driving is an uncommon occurrence, but which might have serious medical and legal implications. While still reported casually and with very few systematized studies, sources underscore mainly the neurological picture and risk factors that will lead herein. Car crashes follow as a rule the event of the stroke. We describe the case of a middle-aged patient that had an incomplete loss of the car control, with a crash of minor severity and with no external signs of trauma. In spite that the patient underwent successfully a thrombectomy intervention, he presented continuously with refractory hypotension. The clinical picture raised suspicions of an internal blood loss and whole body angiography detected the rupture of the mesenteric artery. This sequence of events (stroke while driving - crash - seatbelt injury - mesenteric rupture) is probably not reported before, but mechanistically an unlucky combination to be kept in mind while dealing with such cases.
\end{abstract}

Keywords: Stroke while driving; Mesenteric artery rupture; Minor trauma; Refractory hypotension; Seatbelt injuries

How to cite this paper: Basha, E., Ranxha, E., Leka, V., \& Vyshka, G. (2021). A Case Report of Stroke While Driving: Minor Traumas Might be not Minor at all. Global Journal of Medical Case Reports, 1(1), 19-23. Retrieved from https://www.scipublications.com/journal/index.php/gjmcr/article/view/169

Received: October 2, 2021 Accepted: November 11, 2021 Published: November 12, 2021

Copyright:@ 2021 by the authors Submitted for possible open access publication under the terms and conditions of the Creative Commons Attribution (CC BY) license (http://creativecommons.org/licenses /by/4.0/).

\section{Introduction}

Stroke is a neurological disorder of variable gravity, associated with serious figures of morbidity and mortality. The dichotomy between ischemic and hemorrhagic stroke has clear therapeutic implications. A diversity of risk factors are identified, that in fact are implied with vascular events of all natures (cerebrovascular, cardiovascular).

With the increased use of personal vehicles for everyday life, it has become clear that persons are spending more time driving. Already five years ago, some reports suggested Americans spend more than 50 minutes daily behind the wheel [1]. Apart from difficulties faced during driving (traffic jams, bumpy roads, stress); this mere figure of time spent behind the wheel will explain why stroke cannot be considered extraordinary in this setting.

In fact, there are few studies related to stroke while driving [2]. Inamasu et al. have discussed in details causes that might predispose a driver having an ischemic stroke while on the wheel, among other:

a. uninterrupted sitting while driving may lead to arterial hypercoagulability;

b. driving without drinking water for hours, will cause subsequent dehydration and hemoconcentration;

c. head rotation for shoulder checking, that will predispose drivers to develop cervical artery dissection [2].

Apart from being a neurological emergency, stroke while driving is a traumatic event. Hence, its reporting comes more from sources dealing with traffic injuries that will follow the loss of car control due to stroke itself. In some cases, drivers might be able to have some control before full neurological symptomatology installs (hemiplegia, loss of 
conscience, visual field defect) [3]. Car crashes in such circumstances are unavoidable, and traumatic injuries will occur.

\section{Case Report}

We report the case of a Caucasian male, aged 54 years. He left home early in the morning (6:30) for work, but was found with the car crashed some hundreds meters away from the parking slot.

Paramedics rushed in the scene, and the patient was unresponsive. No further injuries were visible. The patient was immediately transferred to the emergency room (ER) of the University Hospital Centre in Tirana.

\subsection{Clinical findings}

Upon admission, the patient was globally aphasic and a right hemiplegia was present. He presented no visible hematomas or ecchymoses. The relatives referred that he was suffering from hypertension, and treated with ACE-inhibitors during the last two years. The patient suffered from no further diseases or medical conditions.

Blood pressure values at the ER were $90 / 50 \mathrm{mmHg}$, with a blood rate of $95 \mathrm{bpm}$. The neurological evaluation through NIHSS (National Institutes of Health Stroke Scale) scored 24 points (out of a maximum of 42, which corresponds to the most severe situation) [4, 5].

\subsection{Diagnostic assessment}

A routine non-enhanced head CT on the ER was within norm. Diffusion-weighted images on the magnetic resonance imaging showed instead a fresh capsular thalamic infarction on the territory of left middle cerebral artery (Figure 1).

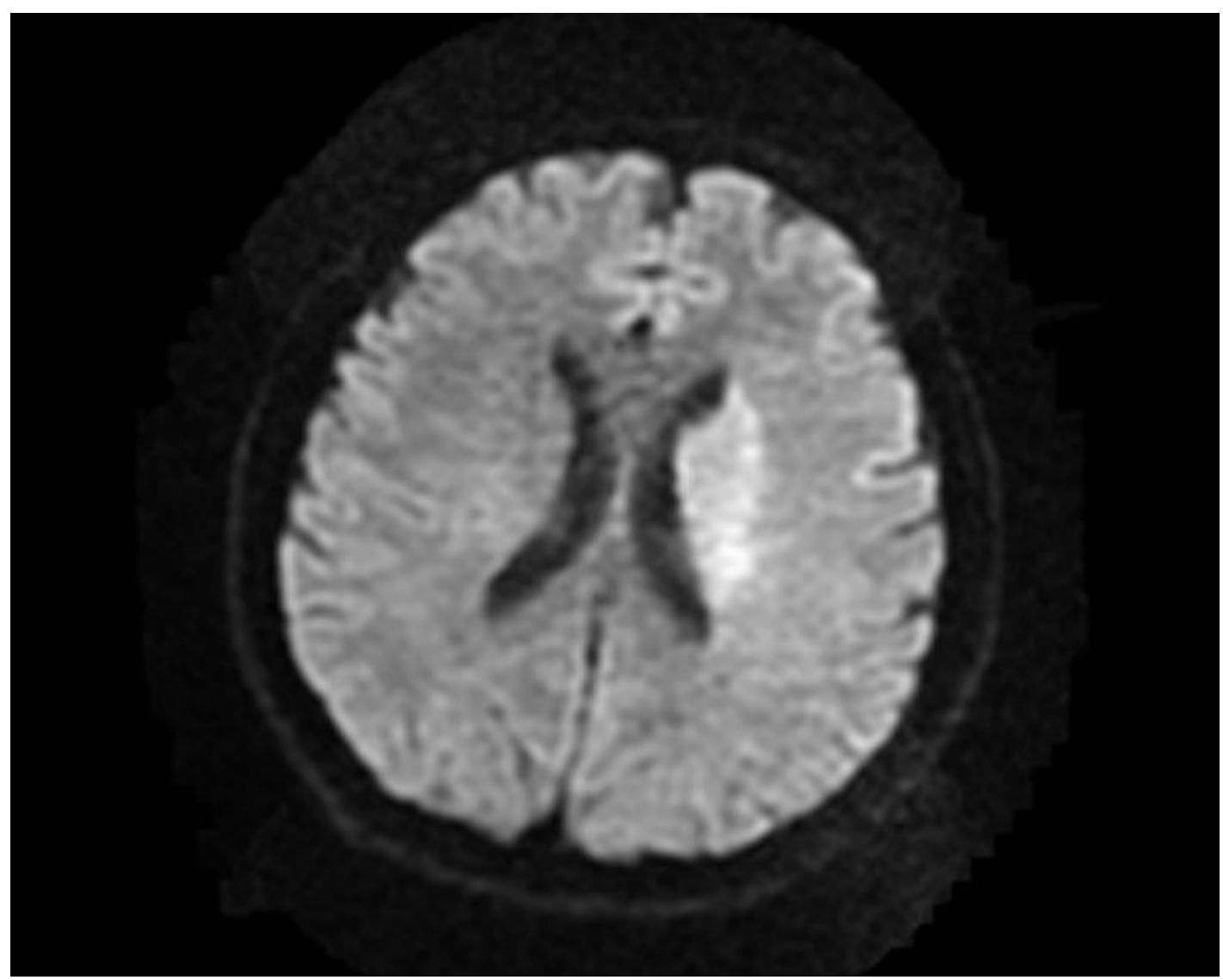

Figure 1. DWI-MRI brain axial image five hours after installation of the motor deficit. 


\subsection{Therapeutic intervention}

The persistence of right hemiplegia with head and eyes' deviation (Prévost's sign) suggested a brain infarction [6]. A digital subtraction angiography (DSA) showed the complete occlusion of the proximal M1 portion of the left middle cerebral artery (Figure 2a). The endovascular thrombectomy was performed at the angio suite. A control DSA documented the complete re-establishing of the perfusion (Figure 2b).

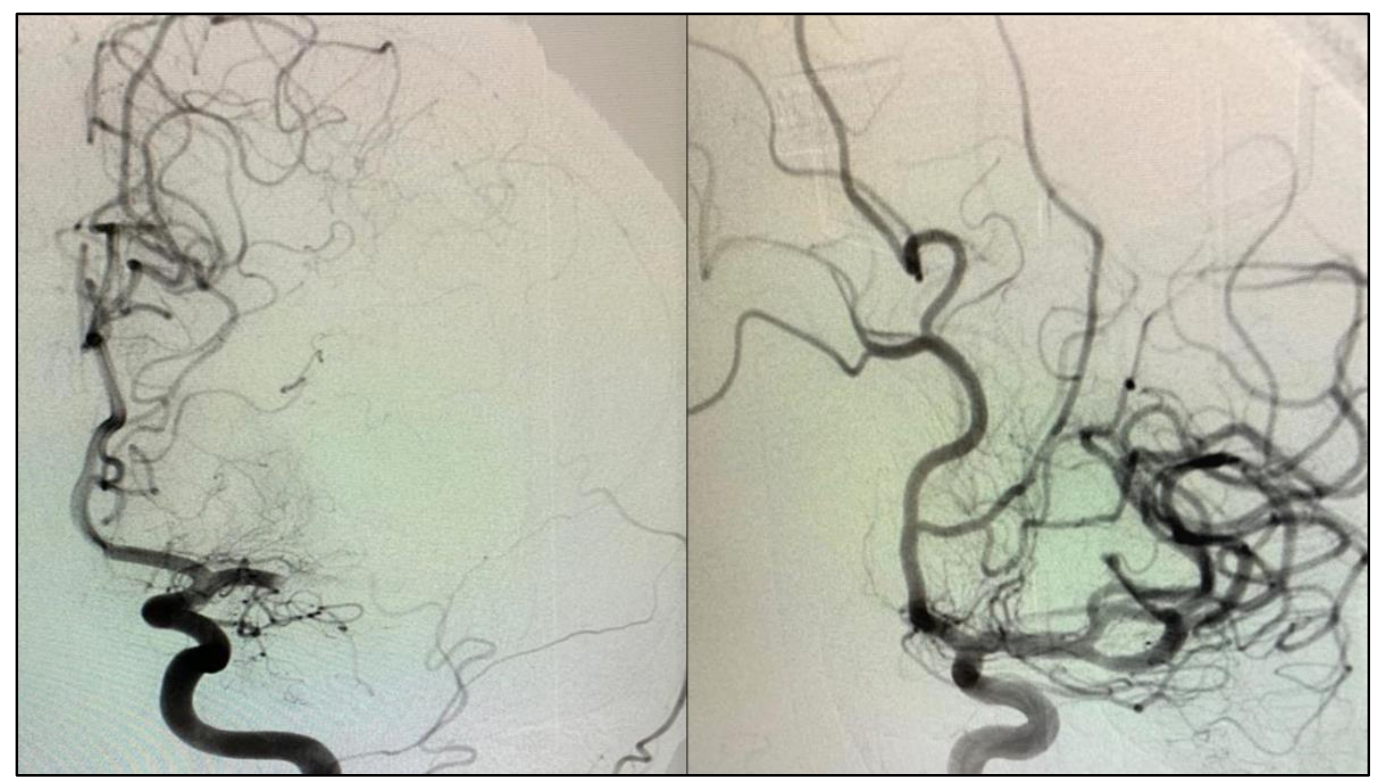

Figure 2. (a) (left inset): digital subtraction angiography showing complete occlusion of left middle cerebral artery. (b) (right inset): normalized perfusion after thrombectomy.

\subsection{Follow-up and outcome}

Following the procedure of thrombectomy, the patient was hemodynamically unstable and hypotension persisted (blood pressure $70 / 50 \mathrm{mmHg}$ ) with compensatory sinus tachycardia, despite intravenous infusions. Under these conditions, a total-body CT angiography was immediately performed to explain the refractory hypotension. Intra-abdominal bleeding with extravasation of the contrast (more prominently during the venous phase) as shown in the Figure 3 was apparently the cause of the hypotension.
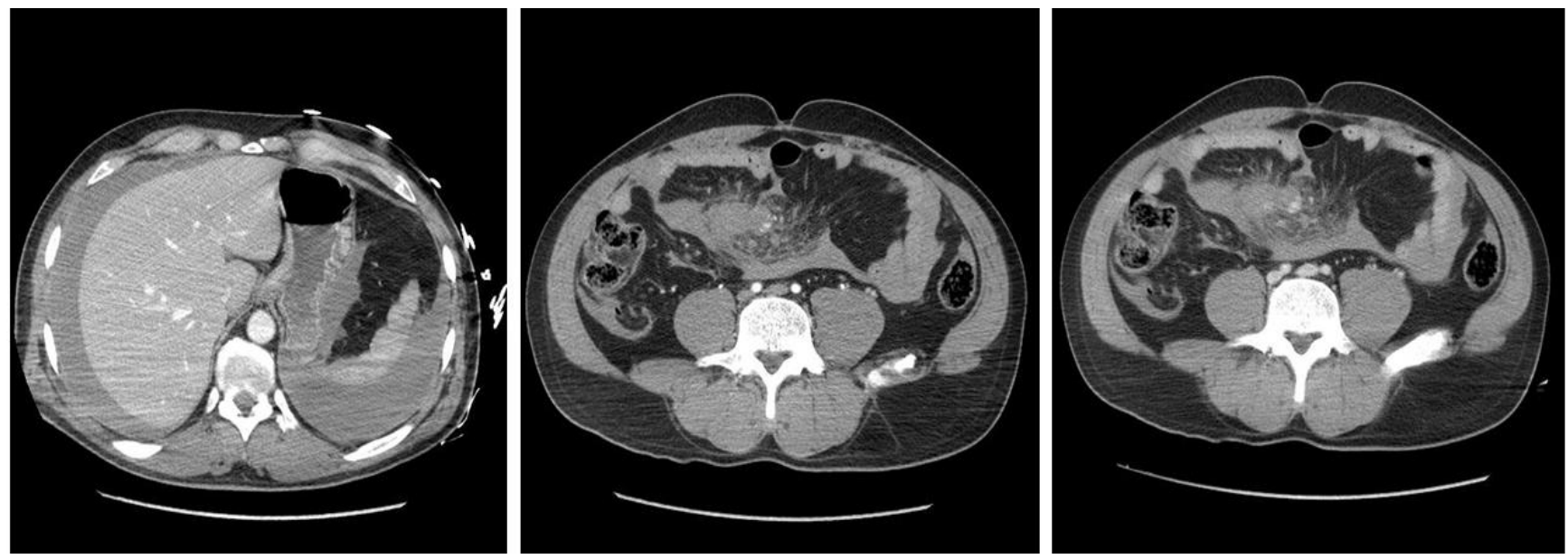

Figure 3. (a) (left inset): contrast-enhanced abdominal angiography with hemorrhagic effusion. (b) (middle inset): extravasation of the contrast at the level of mesenteric artery [arterial phase]. (c) (right inset): increased extravasation during the venous phase of the imaging. 
With the typical images of contrast extravasation at the level of superior mesenteric artery, we suspected a rupture of the latter. Following a surgical consultancy, he was operated within the next hour after the abdominal CT angiography data were collected.

The mesenteric artery rupture was repaired through surgery under general anaesthesia and the patient was treated with supportive therapy at the intensive care unit for the following three days. Upon stabilization of the general conditions, the patient relocated at the neurological ward, with rehabilitation measures put in place. At a one-month follow-up, he presented still with a slight motor dysphasia but was able to walk independently, with almost complete recovery of the motor functions of the right extremities.

\section{Discussion}

The event of a stroke while driving has multiple medical implications. As a rule drivers will loss control of the car, and the following crash should raise suspicions of internal trauma even if there are no external signs. In our case, the driver was using the safety belt, and the inspecting team at the scene found no signs of blunt trauma.

However, hypotension is a rarity in a stroke patient, and when present generally is an ominous sign [7]. There is still no universally accepted 'normal range' for blood pressure values following a stroke, but hypotension might be deleterious as hypertension itself that has ever since been recognized as a major risk factor for vascular events [8]. Some authors have even proposed therapeutic schemata to face post-stroke hypotension, due to clear neurological deterioration that follows its appearance [9].

As described above in our case, stroke while driving is a rarity not evaluated systematically from authors. Even case reports are scarce, with some of them in the literature [10]. With majority of sources focusing instead at the ability of patients to turn back to drive after suffering a stroke, however we should point out some particularities of a stroke while driving:

a. Even if drivers do not lose completely the control over the car, generally a crash is unavoidable. Thus, stroke while driving is as well a traumatic event, and not merely a neurological issue;

b. Minor traumas that are mitigated from seatbelts or airbags might be seriously complicated through internal hemorrhage, as in our case; even in the absence of external signs of trauma;

c. Seatbelt itself or other circumstances might produce complications, here including soft tissues injuries and arterial rupture [11, 12]. Furthermore, blunt trauma - especially in the deceleration phase - might be able to complicate an apparently trivial occurrence [13].

d. Unexplained hypotension in such an unlucky setting should raise doubt about internal blood losses.

A careful diagnostic workup of unexplained hypotension will of course require a whole body CT angiography, whose technicalities are out of the scope of this paper [14].

\section{Conclusion}

Stroke while driving is a rarely reported entity; however, with increasing number of people using personal cars, and an even more aging drivers' population, the medical staff should be aware of such a condition.

Consequence of stroke while driving might be not merely neurological, as the disease itself. The car crash of whatever gravity can subsequently cause blunt body traumas that sometime can go unnoticed. Especially, when facing an acute neurological event in this setting accompanied with refractory, unexplained hypotension, a total body CT imaging might be of value. This will timely detect any internal hemorrhage and eventually the respective source, as in our case, and will guide clinicians toward interventions of efficacy. 


\section{Authors' contribution}

EB wrote the introduction; EB, ER, VL and GV wrote the case report; GV wrote the discussion section. All authors reviewed the references and approved the final version.

Conflict of interest: nothing to declare.

Funding: no funding received for the present paper.

Ethical statements: informed consent obtained.

\section{References}

[1] https://aaafoundation.org/wp-content/uploads/2018/02/18-0019_AAAFTS-ADS-Research-Brief.pdf [Last accessed August 20th, 2021].

[2] Inamasu J, Nakatsukasa M, Tomiyasu K, Mayanagi K, Nishimoto M, Oshima T, Yoshii M, Miyatake S, Imai A. Stroke while driving: Frequency and association with automobile accidents. Int J Stroke. 2018 Apr;13(3):301-307.

[3] Finelli PF, Lee N. Stroke and automobile accidents. Conn Med. 1996 Mar;60(3):145-7.

[4] Brott T, Adams HP Jr, Olinger CP, Marler JR, Barsan WG, Biller J, Spilker J, Holleran R, Eberle R, Hertzberg V, et al. Measurements of acute cerebral infarction: a clinical examination scale. Stroke. 1989 Jul;20(7):864-70.

[5] Kwah LK, Diong J. National Institutes of Health Stroke Scale (NIHSS). J Physiother. 2014 Mar;60(1):61.

[6] Fruhmann Berger M, Pross RD, Ilg U, Karnath HO. Deviation of eyes and head in acute cerebral stroke. BMC Neurol. 2006 Jun 26;6:23.

[7] Löwhagen Hendén P, Rentzos A, Karlsson JE, Rosengren L, Sundeman H, Reinsfelt B, Ricksten SE. Hypotension During Endovascular Treatment of Ischemic Stroke Is a Risk Factor for Poor Neurological Outcome. Stroke. 2015 Sep;46(9):2678-80.

[8] Robinson TG, Potter JF. Blood pressure in acute stroke. Age Ageing. 2004 Jan;33(1):6-12.

[9] Kim HJ, Kang DW. Induced hypertensive therapy in an acute ischemic stroke patient with early neurological deterioration. J Clin Neurol. 2007 Dec;3(4):187-91.

[10] Akgün UY, Akça HŞ, Kolbaş F, Özdemir S, Algin A, Eroğlu SE. An Unfortunate Coexistence, Ischemic Stroke While Driving. How Often? How Deadly? A Case Report. Anatolian Journal of Emergency Medicine.;3(3):85-8.

[11] Nishino T, Morita S, Sakurai K, Watanabe Y. A giant abdominal hematoma caused by seatbelt injury led to the development of shock. Clin Case Rep. 2015 Aug;3(8):723.

[12] Singla AA, Singla AA. Seatbelt syndrome with superior mesenteric artery syndrome: leave nothing to chance! J Surg Case Rep. 2015 Nov 12;2015(11):rjv148.

[13] Wang RF, Chong CF, Hsu HT, Wang TL, Chen CC. Mesenteric injury caused by minor blunt abdominal trauma. Emerg Med J. 2006 Apr;23(4):e27.

[14] Dreizin D, Munera F. Blunt polytrauma: evaluation with 64-section whole-body CT angiography. Radiographics. 2012 MayJun;32(3):609-31. 